\title{
MJN QUALITY OF LIFE, SELF-RATED HEALTH AND SOCIAL SUPPORT AMONG OLDER ADULT IN THE SAUDI COMMUNITY
}

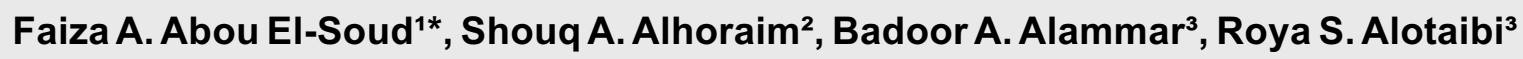 \\ ${ }^{1}$ Community Health Nursing Department, College of Nursing, King Saud bin Abdulaziz University for \\ Health Sciences, Riyadh, Kingdom of Saudi Arabia; King Abdullah International Medical Research \\ Center (KAIMRC), Riyadh, Ministry of National Guard Health Affairs, Saudi Arabia; Assistant \\ Professor of Community Health Nursing, College of Nursing, Menoufiya University, Egypt \\ ${ }^{2}$ Undergraduate Nursing Students, College of Nursing, King Saud Bin Abdul-Aziz University for Health \\ Sciences, Riyadh, Saudi Arabia \\ ${ }^{3}$ King Abdullah International Medical Research Center (KAIMRC), Riyadh, Ministry of National Guard \\ Health Affairs, Saudi Arabia \\ *Corresponding Author's Email: soudf@ksau-hs.edu.sa
}

\begin{abstract}
Background: There is a marked increase in the number of older populations all over the world in recent years, and this progress is projected to accelerate in the physical, psychological, social, and economic problems that affect negatively on their quality of life. Aim: The present study was aimed to explore the associations between quality of life and self-rated health and social support among the older adult population in the Saudi Community. Methods: A cross-sectional and correlational descriptive designs were used. The study sample included 200 older adults who were aged 60 years and above. This study was conducted in different public places in the Western region of Riyadh city - Saudi Arabia such as shopping malls, and mosques. Data was collected through a survey by the self-report questionnaire that included five tools (1) Socio-demographic characteristics and medical health status, (2)Activities of Daily Living and Instrumental Activities of Daily Living Scales, (3)World Health Organization Quality of Life (WHOQOL) scale, (4)Self-Rated Health (SRH) questions and (5)Social Support Rating Scale (SSRS). Pearson correlation coefficient and logistic regression were used in statistical analyses. Results: The findings revealed a negative association between quality of life and older adults' age as well as the number of chronic illnesses. Moreover, there was a positive association between quality of life and patient's gender, marital status, levels of education, patterns of living arrangement, types of care providers, family income sufficiency, functional capacity, self-rated health, and social support. Meanwhile, there is no association between quality of life and older adults' nationality. Conclusion: Chronic illness, social support and age were the greatest significant predictors that have the highest influence on the QOL, while the level of education and family income sufficiency were the lowest significant predictors that have a low influence on the QOL of the older adult participants. Recommendations: The study help to develop prospective intervention strategies that deliver primary health care and early intervention for an older adult and their family caregivers can increase control over the predictors which have a direct influence on the quality of life of the older adults.
\end{abstract}

Keywords: Quality of life, Self-Rated Health, Social Support, Older Adults

\section{INTRODUCTION}

In the recent decade, the number of elderly populations are growing more rapidly than the number of people in any other age group. Consequently, the section of elderly people in the total population is expanding globally; hence population ageing has become a global phenomenon. Therefore, the population ageing is one of the most significant social transformations of the twentyfirst century, with implications for nearly all sectors of society, including labor and financial markets, the demand for goods and services, such as housing, transportation and social protection, as well as family structures and intergenerational ties (The World 
Population Prospects, 2019; Bélanger et al., 2016).

Between 2015 and 2030, the population aged 60 years or over in the world is proposed to rise by $56 \%$, from 901 million to 1.4 billion. In 2050, the universal population of an older adult is predicted to more than twofold its size by 2015 , reaching closely 2.1 billion. Further, the percentage of people aged 80 years or over, is growing even faster than the percentage of older persons globally. Predictions point out that in 2050 the oldest-old will be 434 million, having more than tripled number since 2015, when there were 125 million people over age 80 . Over the next 15 years, the number of older persons is anticipated to grow fastest in Latin America and the Caribbean with an estimated $(71 \%)$ increase in the population aged 60 years or over, followed by Asia (66\%), Africa (64\%), Oceania (47\%), Northern America (41\%) and Europe (23\%) (The World Population Prospects, 2019; Bélanger et al., 2016).

Similarly, the recent estimates in 2019 indicate the population of Saudi Arabia has grown up to 34.14 million, according to the data provided by the World Bank. Additionally, Riyadh, which is the capital of the Kingdom of Saudi Arabia and the largest city in the kingdom, is home to over 4,205,961 million people. Meanwhile, the proportion of elderly people in Saudi Arabia aged 60 and above is predicted to be $25 \%$ of the total population. Moreover, the number of elderly people aged 80 and above is expected to rich 1.6 million (Saudi Arabia-World Bank Data, 2019). This growth of the elderly population segment will reach the highest level in Arabian countries by 2050, for example, Egypt is the largest ranking population above the age 80 years (3.1 million), followed by Algeria (1.7 million) and Morocco (1.4 million). As well as Saudi Arabia is not exceptional from the increased prevalence of aging internationally and average life expectancy of Saudi improved to reach 72.8 for males and 76.9 for females (Saxena, 2008; Karlin, Weil \& Felmban, 2016).

As the population age increases, the current global demographic trends revealed that each group of older persons can expect to live longer and possibly also have fewer adult children as potential sources of support among old age. There were 7 persons in the traditional working ages, 20-64 years, for each older person aged 65 years or over, but by 2050 , there will be 3.5 workingaged persons for each older person in the world, and all major regions except Africa are expected to have potential support ratios of 3.2 or lower. In response to this current trend in population aging, many of the elderly population may have unsatisfactory levels of support (UN, 2015).

According to White et al., (2009), social support is social interactions and networks of relationships that are proposed to provide strength and well-being of the individual. On the other hand, social support has been an important social determinant of health because it helps individuals, particularly elderly age group for reaching the physical, emotional needs and will diminish the effects of stress and at the same time provide optimistic result in elderly that will lead to a positive influence on the general health status of the older population (Dangi, 2016; Bryła, Burzyńska \& Maniecka-Bryła, 2013)

Some research studies highlight on social support as a relevant feature of the quality of life, whereas the quality of life is described as a way that reflects how the persons perceive themselves so that they can function physically, emotionally, mentally, and socially. Furthermore, the quality of life is portrayed as a life without damage, functional limitation, disability, or handicap (White et al., 2009; Porta, 2008). Therefore, the beneficial outcome of social support and social integration on health and survival of the elderly are strengthened along with coping and recovery from the illness. This means a good social support that leads to a positive quality of life. On contradictory, lack of social support, social isolation and lack of neighborhood had a negative impact on immune, metabolic, and cardiovascular systems as well as healthrelated behaviors, which means social isolation and insufficient social support are leading to negative qualityof-life (White et al., 2009; WHO, 2015).

In addition, the epidemiological researches and several theories focus on self-rating of health (SRH) as an assessment tool to measure health perceptions, a person's has his/her own health appraisal of general health which may reflect indications of ill health that are not included in the medical examination. While another theory reported that SRH reflects the lifestyle, psychosocial and socio-demographic status that may have a negative impact on health (Kaplan \& Camacho, 1983; Kobayashi et al., 2013; Martinez-Martin et al., 2012). In addition, investigations of the health of the elderly population revealed that SRH is a valid and reliable tool to measure health as well as a predictor of mortality among the elderly population age group and also there are strong association between SRH and morbidity and disability as well as the social and economic factors (Raggi et al., 2016).

Although there are extensive literature reviews which indicate that there are associations between QOL and low social support and poor perceived health, 
including health-related quality of life. But still, there is a lack of researches regarding the quality of life, selfrated health and social support among the elderly population in Saudi Arabia, Riyadh. For that reason, this study explores the associations between quality of life, self-rated health and social support among the elderly population; also, to determine the predictors that may influence their quality of life.

\section{Methodology}

A cross-sectional descriptive design was used in the present study to describe the quality of life of the older adult participants in the Saudi community, and how the older adults did their health appraisal as well as how they perceived social support. A correlational descriptive research design was used to explore the associations between quality of life, self-rated health and social support among the older adult population in the Saudi Community.

Research Questions: to achieve the purposes, the following research questions were developed

Q1. What are the levels of quality of life, degree of self-rated health and social support in older adult participants among the study sample in the Saudi community?

Q2. Is there a significant relationship between quality of life, self-rated health and social support among older adult participants in the study sample?

Q3. What are the predictors that may influence the quality of life of older adult participants in study sample?

Research Setting: The data were collected from December 2017 to April 2018. This study was conducted in different public places in the Western region of Riyadh city - Saudi Arabia such as shopping malls, and mosques.

Study Sample: By using G power (power analysis) of $\alpha 0.05$, power 90 , and medium effect size of 0.2 , and using the correlation test, considering the confidence level $95 \%$ and confidence interval $5 \%$, the calculated sample size is 200 older adults (Faul et al., 2009). The target population encompassed older adult population who were chosen by a convenience sampling technique as they were fulfilling the following inclusion criteria: older adult aged 60 years and above, both genders, Saudi and Non-Saudi nationality, and willing to participate in the research. While the exclusion criteria are older adults who are diagnosed with cognitive, psychological and mental problems.
Pilot study: The questionnaire was piloted among 20 older adult populations to assess the clarity and feasibility of the questionnaires and to determine the time frame that is required to fulfill the questionnaire.

Tools of data collection: A self-report questionnaire was administered to the older adult participants to complete with little or no intervention from the researcher. The study used interviews as a method of data collection. This interviewing was conducted by the researchers to gain a deeper insight into specific answers by treating the questionnaire like a meaningful discussion and deducing the validity of each response. The entire questionnaire was initially prepared in English, translated from English word to Arabic and translated back to English by a group of experts. Confidentiality was maintained on all data collection forms by using codes to identify respondents instead of names. The total package of five instruments was used for data collection. The time frame for answering the questionnaire was approximately 20-25 minutes. This questionnaire included five tools:

I. Socio-demographic characteristics and medical health status: These consist of age, gender, nationality, marital status, levels of education, patterns of living arrangement, who is the care provider at home, family income sufficiency and the number of chronic illnesses.

II. 1. Katz Index of Independence in Basic Activities of Daily Living (BADL): It is an instrument to assess functional status as a measurement of the client's ability to perform activities of daily living independently. The Index ranks adequacy of performance in the six functions of bathing, dressing, toileting, transferring, continence, and feeding (Katz et al., 1970).

II. 2. Instrumental Activities of Daily Living (IADL): It is an instrument to assess independent living skills. These skills are measured more complex than the basic activities of daily living. The instrument is most useful for identifying how a person is functioning at present and for identifying improvement or deterioration over time. There are 8 domains of function measured with IADL scale that include using a telephone, shopping, food preparation, housekeeping, laundry, mode of transportation, responsibility for own medications, and the ability to handle finances (Lawton \& Brody, 1969).

In the current study, the participants were asked to report on the ability to perform the task without help, rated as follows: $1=$ independent and $2=$ dependent. The sum scores for ADL \& IADL ranged between 0-28, with 
higher scores indicating that the elderly participants are dependent and lower scores indicating to the elderly participants are independent.

The reliability of the instruments (ADL/IADL) has consistently demonstrated its utility in evaluating functional status in the elderly population. The ADL was high internal consistency and a reliability coefficient (Cronbach's alpha $=0.91$ ), excellent test-retest reliability (coefficient correlation, ICC $=0.99$ ). While several studies have been performed to test the Lawton IADL scale psychometric properties. The Lawton IADL Scale was originally tested concurrently with Inter-rater reliability established at 0.85 (Katz et al., 1970; Lawton \& Brody, 1969).

\section{World Health Organization Quality of Life (WHOQOL):}

It is the instrument used to assess the individual's perceptions in the context of their culture and value systems, and their personal goals, standards, and concerns. It comprised of 26 items, which measure the following broad domains: physical health, psychological health, social relationships, and environment. This tool is a generic questionnaire that is a short version of the WHOQOL-100 scale (Skevington, Lofty \& O'Connell, 2004). The participants' response options ranged from 1 (unsatisfied) to 5 (satisfied). This instrument interpreted the scores that have four domains, namely, physical health (seven items), psychological health (six items), social relations (three items) and environment (eight items). The domain scores of the WHOQOL-BREF are computed by summation of the raw scores of the constituent items onto a $0-100 \%$ scale (Skevington, Lofty \& O'Connell, 2004). The respondents' rate is given on a 5point scale ranging from 1 (very poor) to 5 (very good). A higher score indicating that the elderly participants have better QOL and lower scores that the elderly participants have a worse QOL.

The reliability of the WHOQOL-BREF instrument was assessed through internal consistency (Cronbach's alpha) and test-retest coefficient (i.e., Pearson's correlation). The results for each sub-scale as follows: Overall WHOQOL items $(0.93)$, physical health $(0.80)$, psychological health (0.77), social relationships $(0.69)$, and environment $(0.83)$. The validity of this instrument was assessed utilizing the convergent, the discriminant and content validity and appears to be valid with sufficient sensitivity. The intra-class correlation for the test-retest statistic and the internal consistency values for the full questionnaire and the domains had a Cronbach's alpha $(\geq 0.75)$ (WHOQOL, 1997).

IV. Self-Rated Health (SRH): This is used to assess the health status of the older adult participants in the current study by measuring three questions: (Bjorner et al., 1996)

In the current study, a higher value is equivalent to higher ratings of health (good) and the lower value is equivalent to lower ratings of health (poor).

V. Social Support Rating Scale (SSRS): This instrument contained 19 functional support items to measure four dimensions of social support: (1) emotional / informational support (the expression of positive affect, empathetic understanding, and the encouragement of expressions of feelings), (2) tangible support (the provision of material aid or behavioral assistance), (3) positive social interaction (the availability of other persons to do fun things with you and involving expressions of love and affection), and (4) affectionate support (involving expressions of love and affection). Each subscale is measured by 10 -items on a 5-point scale ranging from "None of the time" $=1$ score to "All of the time" $=5$ scores. A higher score for each subscale or the overall social support index indicates that the participants perceived social support.

The internal-consistency reliability estimation is high for all support subscales measures. This instrument is reliable (all alphas $>0.91$ ) and stable over time and construct validity is supported. Item-scale correlations ranged from 0.72-0.87 for tangible support scale, 0.800.86 for the affection scale, $0.82-90$ for the emotional scale, and 0.87-088 for the positive interaction scale (Sherbourne \& Stewart, 1991).

In the current study, these tools were adapted and translated from English to the Arabic language by independent translators for the convenience of its contents and tested for content validity by different experts in the field of community health nursing and geriatric nursing. The required modification was done accordingly. This version was checked by the researchers of the present study to assess the similarity between the original version and the back-translated version to avoid discrepancies. The intra-class correlation for the test-retest reliability and the internal consistency values was measured for all the scales where the overall QOL, SRH, SSRS, ADL \& IADL had a Cronbach's alpha $(0.82 ; 0.84 ; 0.78 ; 0.84 ; 0.84)$. 
Data analysis: Data entry and analysis were performed by using SPSS for windows version 22 . The responses in the completed questionnaires were coded and entered a data template. Descriptive statistical analysis as frequencies or percentages, mean and standard deviation (SD) were used for describing data. Pearson correlation coefficient ( $r$ ) was employed to address the relationship between quality of life, selfrated health and social support among the study samples. Logistic regression was used to identify the significant predictive factors that affect the quality of life of the older adult participants. The statistical significance value was set at $P<0.05$.

Ethical Considerations: In this study, the data collection commenced after ethics approval was granted from the Institutional Review Board (IRB) of King Abdullah International Medical Research Center (KAIMARC). A consent form was provided to all eligible participants by the investigators, where all study participants were fully informed regarding the purpose of the study and expectations of participation. Also, the researchers were clarified that there are no potential risks associated with their participation and they have the right to withdrawal from the research without penalty. Confidentiality and privacy were completely protected; no identifiers or personal information was collected or stored.

\section{RESULTS}

Table 1 showed the mean scores of the WHOQOL domains among the older adult participants in the study sample. The results in this table indicated that study participants had a better quality of life satisfaction, where the highest mean scores \pm SD were related to the environment domain and social relationships domain $(81.0 \pm 8.22 ; 73.0 \pm 10.25)$ respectively, while the low mean scores $\pm \mathrm{SD}$ was related to the physical health domain (63.0 \pm 11.24$)$, and psychological health domain was $69.0 \pm 14.65$, and the overall quality of life satisfaction was $78.26 \pm 13.32$. In addition, this table displayed the mean scores of the three measures of selfrated health among the older adult participants in the study sample. In this table, the results specified those study participants had a good rating of their general health status (SRH-5) where the mean score \pm SD was $3.72 \pm 1.20$, also they are regarding their health (SRH-7) at a good rating level where mean score was $5.23 \pm 1.65$. Besides, the mean score \pm SD for their assessment of general health status compared to the others of their age (SRH-age) also had a good rating (3.66 \pm 1.12$)$.
Table 1: Mean Scores of the WHOQOL Domains among the Older Adult Participants in the Study Sample

\begin{tabular}{|l|c|c|c|}
\hline WHOQOL Domains & $\begin{array}{c}\text { No. of } \\
\text { Items }\end{array}$ & Mean & SD \\
\hline Physical Health & 10 & 63.0 & 11.24 \\
\hline Psychological Health & 10 & 69.0 & 14.65 \\
\hline Social Relationships & 10 & 73.0 & 10.20 \\
\hline Environment & 10 & 81.0 & 8.22 \\
\hline Overall QOL & 40 & 78.26 & 13.32 \\
\hline
\end{tabular}

Table 2: Mean Scores of the Three Measures of SelfRated Health among the Older Adult Participants in the Study Sample

\begin{tabular}{|l|c|c|c|}
\hline Self-Rated Health & Response Rating & Mean & SD \\
\hline SRH-5 & $1-5$ & 3.72 & 1.20 \\
\hline SRH-7 & $1-7$ & 5.23 & 1.65 \\
\hline SRH-age & $1-5$ & 3.66 & 1.12 \\
\hline
\end{tabular}

Table 3 revealed the mean scores of the social support dimensions among the older adult participants in the study sample. The results in this table point out that the older adult participants are perceived a highlevel social support, where the mean score $\pm \mathrm{SD}$ of the emotional support dimension was $32.11 \pm 3.45$, tangible support dimension was $18.31 \pm 1.86$, affectionate support dimension was $21.45 \pm 2.64$, positive social dimension was $7.12 \pm 2.32$, and overall social support was $68.73 \pm 3.42$.

Table 3: Mean Scores of the Social Support Dimensions among the Older Adult Participants in the Study Sample

\begin{tabular}{|l|c|c|c|}
\hline \multicolumn{1}{|c|}{$\begin{array}{c}\text { Social Support } \\
\text { Dimensions }\end{array}$} & $\begin{array}{c}\text { No. of } \\
\text { Items }\end{array}$ & Mean & SD \\
\hline Emotional Support & 8 & 32.11 & 3.45 \\
\hline Tangible Support & 4 & 18.31 & 1.86 \\
\hline Affectionate Support & 5 & 21.45 & 2.64 \\
\hline Positive Social Interaction & 2 & 7.12 & 2.32 \\
\hline Overall Social Support & 19 & 68.73 & 3.42 \\
\hline
\end{tabular}

Table 4 showed the correlation between the quality of life and health-related factors of the older adult participants in the study sample. The results revealed that the QOL had a negative significant correlation with the older adults' age $(r=-0.392, p=0.016)$, and the number of chronic illness $(r=0.610, p=0.000)$. Meanwhile the QOL had a positive significant correlation with gender $(r=0.602, p=0.037)$, levels of education $(r=0.843, p=0.014)$, marital status $(r=0.215$, $p=0.028)$, patterns of living arrangement $(r=0.819$, 
$p=0.016)$, type of care providers $(r=0.713, p=0.026)$, family income sufficiency $(r=0.361, p=0.056)$, and functional capacity $(r=0.560, p=0.000)$. Moreover, there is no association between QOL and the nationality of the older adult participants $(r=0.184, p=0.049)$.

The indent results of this table 4 revealed the mean age of the study sample was $(68.8 \pm 8.14)$. Whereas, young-old group had the highest percent of better QOL (34.0\%) compared to the other aged groups "old and oldest-old groups". Furthermore, the male had the highest percent of better QOL (34.5\%) compared to the female. Additionally, married older adult participants had the highest percent of better QOL (41.5\%) compared to single, divorced, and widowed. Also, literate participants had the highest percent of better QOL (50.0\%) compared to illiterate. Also, the results declared that the older adult participants who are living with family had the highest percent of better QOL (48.0\%) compared to the participants who are living with their significant relative or living with home-made. Likewise, the participants who received care from their children and spouse had the highest percent of good QOL $(23.0 \% \& 19.0 \%$ respectively) compared to the participants who received care from home-made and nurse. The older participants who have family income sufficiency had the highest percent of better QOL (50.0\%) compared to the participants who have family income insufficiency. On the other hands, the older participants who had fewer chronic illnesses had the highest percent of better QOL $(33.5 \%)$ compared to the participants who had a greater number of chronic illness. Also, the independent older adult participants had the highest percent of better QOL $(62.5 \%)$ compared to the dependent older adult participants.

Table 4: Correlation between Quality of life and Health-Related Factors of the Older Adult Participants in the Study Sample

\begin{tabular}{|c|c|c|c|c|}
\hline \multirow{3}{*}{ Health-Related Factors } & \multirow{3}{*}{$\begin{array}{c}\text { Study Sample }(\mathrm{n}=\mathbf{2 0 0}) \\
\mathrm{n}(\%)\end{array}$} & \multicolumn{2}{|c|}{ Quality of Life Satisfaction } & \multirow{3}{*}{$\begin{array}{c}r \\
\text { (p-value) }\end{array}$} \\
\hline & & Better $(n=135)$ & Worse $(n=65)$ & \\
\hline & & n (\%) & n (\%) & \\
\hline $\begin{array}{l}\text { Age } / y r \\
\text { Young -old }(60-\text { years }) \\
\text { Old }(75 \text {-years }) \\
\text { Oldest-old }(85+\text { years }) \\
\text { Mean + SD }(68.8+8.14)\end{array}$ & $\begin{array}{c}100(50.0) \\
89(44.5) \\
11(5.5)\end{array}$ & $\begin{array}{c}68(34.0) \\
57(28.5) \\
10(5.0)\end{array}$ & $\begin{array}{c}32(16.0) \\
32(16.0) \\
1(0.5)\end{array}$ & $\begin{array}{c}-0.392 \\
\left(0.016^{*}\right)\end{array}$ \\
\hline $\begin{array}{l}\text { Gender } \\
\text { Male } \\
\text { Female }\end{array}$ & $\begin{array}{c}98(49.0) \\
102(51.0)\end{array}$ & $\begin{array}{l}69(34.5) \\
66(33.0)\end{array}$ & $\begin{array}{l}29(14.5) \\
36(18.0)\end{array}$ & $\begin{array}{c}0.602 \\
\left(0.037^{*}\right)\end{array}$ \\
\hline $\begin{array}{l}\text { Nationality } \\
\text { Saudi } \\
\text { Non-Saudi }\end{array}$ & $\begin{array}{c}188(94.0) \\
12(6.0)\end{array}$ & $\begin{array}{c}129(64.5) \\
6(3.0)\end{array}$ & $\begin{array}{c}59(29.5) \\
6(3.0)\end{array}$ & $\begin{array}{c}0.184 \\
\left(0.049^{*}\right)\end{array}$ \\
\hline $\begin{array}{l}\text { Marital Status } \\
\text { Single } \\
\text { Married } \\
\text { Divorced } \\
\text { Widowed }\end{array}$ & $\begin{array}{c}9(4.5) \\
111(55.5) \\
37(18.5) \\
43(21.5)\end{array}$ & $\begin{array}{c}2(1.0) \\
83(41.5) \\
22(11.0) \\
28(14.0)\end{array}$ & $\begin{array}{c}7(3.5) \\
28(14.0) \\
15(7.5) \\
15(7.5)\end{array}$ & $\begin{array}{c}0.215 \\
\left(0.028^{*}\right)\end{array}$ \\
\hline $\begin{array}{l}\text { Levels of Education } \\
\text { Literate } \\
\text { Illiterate }\end{array}$ & $\begin{array}{c}149(74.5) \\
51(25.5)\end{array}$ & $\begin{array}{l}100(50.0) \\
35(17.5)\end{array}$ & $\begin{array}{c}49(24.5) \\
16(8.0)\end{array}$ & $\begin{array}{c}0.843 \\
\left(0.014^{*}\right)\end{array}$ \\
\hline $\begin{array}{l}\text { Patterns of Living Arrangement } \\
\text { Live with family } \\
\text { Live with significant relative } \\
\text { Live with home-made }\end{array}$ & $\begin{array}{c}139(69.5) \\
42(21.0) \\
19(9.5)\end{array}$ & $\begin{array}{c}96(48.0) \\
25(12.5) \\
14(7.0)\end{array}$ & $\begin{array}{c}43(21.5) \\
17(8.5) \\
5(2.5)\end{array}$ & $\begin{array}{c}0.819 \\
\left(0.016^{*}\right)\end{array}$ \\
\hline Who is your care provider at home & & & & \\
\hline $\begin{array}{l}\text { Spouse } \\
\text { Children } \\
\text { House-made } \\
\text { Nurse }\end{array}$ & $\begin{array}{c}58(29.0) \\
72(36.0) \\
63(31.5) \\
7(3.5)\end{array}$ & $\begin{array}{c}38(19.0) \\
46(23.0) \\
48(24.0) \\
3(1.5)\end{array}$ & $\begin{array}{c}20(10.0) \\
26(13.0) \\
15(7.5) \\
4(2.0)\end{array}$ & $\begin{array}{c}0.713 \\
\left(0.026^{*}\right)\end{array}$ \\
\hline
\end{tabular}




\begin{tabular}{|c|c|c|c|c|}
\hline $\begin{array}{l}\text { Family Income Sufficiency } \\
\text { Sufficient } \\
\text { Insufficient }\end{array}$ & $\begin{array}{c}152(76.0) \\
48(24.0)\end{array}$ & $\begin{array}{c}100(50.0) \\
13(6.5)\end{array}$ & $\begin{array}{l}52(26.0) \\
35(17.5)\end{array}$ & $\begin{array}{c}0.361 \\
\left(0.056^{*}\right)\end{array}$ \\
\hline $\begin{array}{l}\text { Number of Chronic Illness } \\
1 \\
2 \\
>3\end{array}$ & $\begin{array}{l}95(47.5) \\
76(38.0) \\
29(14.5)\end{array}$ & $\begin{array}{c}67(33.5) \\
55(27.5) \\
13(6.5)\end{array}$ & $\begin{array}{c}28(14.0) \\
21(10.5) \\
16(8.0)\end{array}$ & $\begin{array}{c}-0.610 \\
\left(0.000^{* *}\right)\end{array}$ \\
\hline $\begin{array}{l}\text { Functional Capacity } \\
\text { Dependent } \\
\text { Independent }\end{array}$ & $\begin{array}{c}48(24.0) \\
152(76.0)\end{array}$ & $\begin{array}{c}10(5.0) \\
125(62.5)\end{array}$ & $\begin{array}{l}38(19.0) \\
27(13.5)\end{array}$ & $\begin{array}{c}0.560 \\
\left(0.000^{* *}\right)\end{array}$ \\
\hline
\end{tabular}

Table 5 displayed the correlation between the quality of life and self-rated health of the older adult participants in the study sample. The results showed that there is a statistically significant correlation between the quality of life and self-rated health among the participants. Whereas, the findings reflected that the study participants who had a better QOL, those are the one who had a good rating heath at the three levels of measurement (SRH-5, SRH-7, and SRH-age) at a significant level $(r=0.320, p=0.000 ; r=0.268, p=0.003$; $r=0.337, p=0.001$ respectively).

Table 5: Correlation between Quality of Life and SelfRated Health of the Older Adult Participants in the Study Sample

\begin{tabular}{|c|c|c|c|c|}
\hline \multirow{3}{*}{$\begin{array}{c}\text { Self-Rated } \\
\text { Health } \\
\text { (SRH) }\end{array}$} & \multirow{3}{*}{$\begin{array}{c}\begin{array}{c}\text { Study } \\
\text { Sample } \\
(\mathrm{n}=200)\end{array} \\
\mathrm{n}(\%)\end{array}$} & \multicolumn{2}{|c|}{$\begin{array}{l}\text { Quality of Life } \\
\text { Satisfaction }\end{array}$} & \multirow{3}{*}{$\begin{array}{c}r \\
\text { ( } p \text {-value })\end{array}$} \\
\hline & & \multirow{2}{*}{$\begin{array}{r}\begin{array}{c}\text { Better } \\
(n=135)\end{array} \\
n(\%)\end{array}$} & \multirow{2}{*}{$\begin{array}{r}\begin{array}{r}\text { Worse } \\
(n=65)\end{array} \\
n(\%)\end{array}$} & \\
\hline & & & & \\
\hline SRH -5 & & & & \\
\hline Good & $87(43.5)$ & $69(34.5)$ & $18(9.0)$ & 0.320 \\
\hline Fair & $83(41.5)$ & $59(29.5)$ & $24(12.0)$ & $(0.000 * *)$ \\
\hline Poor & $30(15.0)$ & $7(3.5)$ & $23(11.5)$ & \\
\hline \multicolumn{4}{|l|}{ SRH -7 } & \multirow{4}{*}{$\begin{array}{c}0.268 \\
(0.003 * *)\end{array}$} \\
\hline Good & $78(39.0)$ & $59(29.5)$ & $19(9.5)$ & \\
\hline Fair & $85(42.5)$ & $63(31.5)$ & $22(11.0)$ & \\
\hline Poor & $37(18.5)$ & $13(6.5)$ & $24(12.0)$ & \\
\hline \multicolumn{4}{|l|}{ SRH -Age } & \multirow{4}{*}{$\begin{array}{c}0.337 \\
\left(0.001^{* *}\right)\end{array}$} \\
\hline Good & $93(46.5)$ & $76(38.0)$ & $17(8.5)$ & \\
\hline Fair & $76(38.0)$ & $51(25.5)$ & $25(12.5)$ & \\
\hline Poor & $31(15.5)$ & $8(4.0)$ & $23(11.5)$ & \\
\hline
\end{tabular}

Table 6 presented the correlation between the quality of life and social support dimensions among the older adult participants in the study sample. The results indicated that there a statistically significant correlation between the quality of life and social support of the older participants. Whereas, the results revealed that there was a significant correlation between QOL and overall social support at a significant value $(r=0.711, p=0.000)$. On the other hands, the findings pointed out the statistical significant correlation between QOL and all social support dimensions, where the study participants who had a better QOL, those the one who are perceived the highest percentages of emotional support $(62.5 \%)$, tangible support (54.0\%), affectionate support (63.5\%) and positive social interaction (57.5\%) compared to the older participants who did not perceived social support.

Table 6: Correlation between Quality of Life and Social Support Dimensions among the Older Adult Participants in the Study Sample

\begin{tabular}{|c|c|c|c|c|}
\hline \multirow[t]{3}{*}{ Social Support } & \multirow{3}{*}{$\begin{array}{c}\text { Study } \\
\text { Sample } \\
(\mathbf{n}=\mathbf{2 0 0})\end{array}$} & \multicolumn{2}{|c|}{$\begin{array}{c}\text { Quality of Life } \\
\text { Satisfaction }\end{array}$} & \multirow{3}{*}{$\underset{\text { (p-value) }}{r}$} \\
\hline & & $\begin{array}{c}\text { Better } \\
(n=135)\end{array}$ & $\begin{array}{l}\text { Worse } \\
(\mathrm{n}=65) \\
\end{array}$ & \\
\hline & & n (\%) & n(\%) & \\
\hline $\begin{array}{l}\text { Emotional Support } \\
\text { Received } \\
\text { Not Received }\end{array}$ & $\begin{array}{c}140(70.0) \\
60(30.0)\end{array}$ & $\begin{array}{c}125(62.5) \\
10(5.0)\end{array}$ & $\begin{array}{c}15(7.5) \\
50(25.0)\end{array}$ & $\begin{array}{c}0.711 \\
(0.000 * *)\end{array}$ \\
\hline $\begin{array}{l}\text { Tangible Support } \\
\text { Received } \\
\text { Not Received }\end{array}$ & $\begin{array}{c}162(81.0) \\
38(19.0)\end{array}$ & $\begin{array}{c}108(54.0) \\
27(13.5)\end{array}$ & $\begin{array}{c}54(27.0) \\
11(5.5)\end{array}$ & $\begin{array}{c}0.606 \\
(0.000 * *)\end{array}$ \\
\hline $\begin{array}{l}\text { Affectionate Support } \\
\text { Received } \\
\text { Not Received }\end{array}$ & $\begin{array}{c}163(81.5) \\
37(18.5) \\
\end{array}$ & \begin{tabular}{|c|}
$127(63.5)$ \\
$8(4.0)$ \\
\end{tabular} & $\begin{array}{l}36(18.0) \\
29(14.5)\end{array}$ & $\begin{array}{c}0.467 \\
\left(0.000^{* *}\right) \\
\end{array}$ \\
\hline $\begin{array}{l}\text { Positive Social } \\
\text { Interaction } \\
\text { Received } \\
\text { Not Received } \\
\end{array}$ & $\begin{array}{c}121(60.5) \\
79(39.5) \\
\end{array}$ & $\begin{array}{c}115(57.5) \\
20(10.0) \\
\end{array}$ & $\begin{array}{c}6(3.0) \\
59(29.5) \\
\end{array}$ & $\begin{array}{c}0.726 \\
(0.000 * *) \\
\end{array}$ \\
\hline $\begin{array}{l}\text { Overall Social } \\
\text { Support } \\
\text { Received } \\
\text { Not Received }\end{array}$ & $\begin{array}{c}119(59.5) \\
81(40.5)\end{array}$ & $\begin{array}{c}113(56.5) \\
22(11.0)\end{array}$ & $\begin{array}{c}6(3.0) \\
59(29.5)\end{array}$ & $\begin{array}{c}0.711 \\
\left(0.000^{* *}\right)\end{array}$ \\
\hline
\end{tabular}

Table 7 showed the logistic regression analysis for the predictors of quality of life among the older adult participants in the study sample. The results in this table revealed that chronic illness, social support, and older adult's age were the most significant predictors which have a greater influence on the quality of life of the older 
adult participants. Meanwhile, the level of education and family income sufficiency were representatives of the lowest significant predictors.

In this study, the results showed that in the study sample showed statistically significant relation on the QOL. Young-old group (60 years) had four times more quality of life satisfaction compared to the other cohort age groups (old-age group: 75 years) and (old-old group: $85+$ years). In addition, the findings in this study found that the gender of the study sample had a statistically significant influence on the QOL, where the males have two times more in their quality of life satisfaction compared to females.

Table 7: Logistic Regression Analysis for Predictors of Quality of Life among the Older Adult Participants in the Study Sample

\begin{tabular}{|c|c|c|c|c|}
\hline \multirow{2}{*}{ Predictors } & \multirow[b]{2}{*}{$\begin{array}{l}\text { Adj. } \\
\text { OR }\end{array}$} & \multicolumn{2}{|c|}{$95 \%$ CI for OR } & \multirow[b]{2}{*}{$p$-value } \\
\hline & & Lower & Upper & \\
\hline \multicolumn{5}{|l|}{ Age /yr. } \\
\hline $\begin{array}{l}\text { Young-old (60- } \\
\text { years) }\end{array}$ & 4.03 & 2.98 & 8.17 & $0.001 * *$ \\
\hline $\begin{array}{l}\text { Old and above } \\
\text { (75+years) }\end{array}$ & 1 & & & \\
\hline \multicolumn{5}{|l|}{ Gender } \\
\hline Male & 2.09 & 1.32 & 4.72 & $0.041 *$ \\
\hline Female & 1 & & & \\
\hline \multicolumn{5}{|l|}{ Marital Status } \\
\hline $\begin{array}{l}\text { Married } \\
\text { the Other Marital } \\
\text { status (single, } \\
\text { divorced, } \\
\text { widowed) }\end{array}$ & $\begin{array}{c}2.11 \\
1\end{array}$ & 1.07 & 4.24 & $0.053 *$ \\
\hline \multicolumn{5}{|c|}{ Levels of Education } \\
\hline $\begin{array}{l}\text { Literate } \\
\text { Illiterate }\end{array}$ & $\begin{array}{c}1.15 \\
1\end{array}$ & 1.18 & 2.30 & $0.021 *$ \\
\hline \multicolumn{5}{|c|}{ Patterns of Living Arrangement } \\
\hline $\begin{array}{l}\text { Live with family } \\
\text { Live with other } \\
\text { significant } \\
\text { members }\end{array}$ & $\begin{array}{c}3.12 \\
1\end{array}$ & 1.89 & 5.98 & $0.001 * *$ \\
\hline \multicolumn{5}{|l|}{$\begin{array}{l}\text { Who is your care } \\
\text { provider at home? }\end{array}$} \\
\hline $\begin{array}{l}\text { Children } \\
\text { Other care } \\
\text { providers } \\
\text { (Spouse, house - } \\
\text { made, nurses) }\end{array}$ & $\begin{array}{c}2.92 \\
1\end{array}$ & 1.65 & 5.87 & $0.002 * *$ \\
\hline
\end{tabular}

\begin{tabular}{|c|c|c|c|c|}
\hline \multicolumn{5}{|l|}{$\begin{array}{l}\text { Family Income } \\
\text { Sufficiency }\end{array}$} \\
\hline $\begin{array}{l}\text { Sufficient } \\
\text { Insuf ficient }\end{array}$ & $\begin{array}{c}1.04 \\
1\end{array}$ & 1.02 & 2.19 & $0.052 *$ \\
\hline \multicolumn{5}{|l|}{$\begin{array}{l}\text { Number of } \\
\text { Chronic Illness }\end{array}$} \\
\hline $\begin{array}{l}1 \\
2 \text { or more }\end{array}$ & $\begin{array}{c}6.04 \\
1\end{array}$ & 3.78 & 12.23 & $0.000^{*}$ \\
\hline \multicolumn{5}{|c|}{ Functional Capacity } \\
\hline $\begin{array}{l}\text { Dependent } \\
\text { Independent }\end{array}$ & $\begin{array}{c}3.96 \\
1\end{array}$ & 1.99 & 7.98 & $0.001 * *$ \\
\hline \multicolumn{5}{|c|}{ Self -Rated Health } \\
\hline $\begin{array}{l}\text { Good } \\
\text { Poor }\end{array}$ & $\begin{array}{c}2.04 \\
1 \\
\end{array}$ & 1.01 & 4.12 & $0.033 *$ \\
\hline \multicolumn{5}{|l|}{ Social Support } \\
\hline $\begin{array}{l}\text { Perceived } \\
\text { Not Perceived }\end{array}$ & $\begin{array}{c}4.98 \\
1\end{array}$ & 2.07 & $\begin{array}{c}10.1 \\
6\end{array}$ & $0.000 * *$ \\
\hline
\end{tabular}

As reflected by the results in table 7, the marital status had a statistically significant influence on the quality of life satisfaction, where the results indicated that married participants had two times more quality of life satisfaction compared to the other participants who are not-married that means single, divorced, and widowed. The levels of education had a statistically significant influence on the quality of life satisfaction, where the results point out the literate elderly participants had one time more their quality of life satisfaction compared to the illiterate participants in the study sample.

Meanwhile, the patterns of living arrangement had a statistical significant influence on the quality of life satisfaction, where the results specified that the older participants who are living with their family had approximately three times more in their quality of life satisfaction compared to the other participants who are living with their relative. Furthermore, the types care provider at home had a statistically significant influence on the quality of life satisfaction, where the elderly participants who received care from their children had three times more quality of life satisfaction compared to the other care providers (spouse, house-made, and nurses).

The results of this study displayed that family income sufficiency had a statistically significant influence on the quality of life satisfaction; where the older participants who have sufficiency of the family income had better quality of life satisfaction compared to the other participants who have insufficiency of 
family income. On the other hand, the number of chronic illnesses had a statistically significant influence on the quality of life satisfaction, where the older participants who have a smaller number of chronic illnesses had six times more quality of life satisfaction compared to the other participants who have more chronic illnesses. In addition, the functional capacity had a statistically significant influence on the quality of life satisfaction, where the older participants who are independent in their activities of daily living (ADL) and instrumental activities of daily living (IADL) had four times better quality of life satisfaction compared to the other participants who are dependent on their ADL and IADL.

In this study, the results disclosed that the self-rated health had a statistically significant influence on QOL of the older adult participants in the study sample. Furthermore, the results revealed that the older adult participants who have good self-rated health tended to have two times more quality of life satisfaction compared to the others who have poor self-rated health. In addition, the findings in this study found that social support among the older adult participants in the study sample had a statistically significant influence on QOL. On the other hand, the older adult participants who perceived social support had approximately five times better quality of life satisfaction compared to the other older adult participants who did not perceive social support.

\section{DISCUSSION}

Due to the inevitable and irreversible changes associated with the aging process, elderly people are exposed to various factors that influence their quality of life. The findings of this current study showed that most of the elderly participants have a high mean score in their overall QOL satisfaction, self-rated health and social support as well.

The results of the current study showed that those variables have a direct influence on the quality of life satisfaction. The result was shown that the QOL was decreased across the life span, where the percentage of QOL was higher among the young-old group compared to the other cohort old-age groups. In addition, this result displayed that QOL was negatively associated with the older adults' age, particularly the participants who had multiple chronic illnesses. Meanwhile, there was a positive significant association between QOL and the level of functional capacity of the older participants. This result is supported by Mohammad et al., 2017; Pradeep,
2017; Sereyraksmey \& Supaporn, 2017; Laleh, Hamideh \& Arash et al., 2017; Mária, 2016; Michelle, 2016; Tavares, 2015, who carried out several studies in different countries which reported that age of the older adults was a greater determinant affecting the QOL. Furthermore, the results of the present study were consistent with Sereyraksmey \& Supaporn, 2017; Unsar, Dindar \& Kurt et al., 2015 who stated that advancing aged is usually associated with restrictions in the ability to perform activities of daily living and inability to function independently in the basic ADL and IADL. This finding comes in contrast with Laleh, Hamideh \& Arash et al., 2017; Eucharia \& Sam, 2015 that revealed that older adult's age did not influence the QOL. This difference may be related to the different of the mean age of the studied samples, as the elderly people are more vulnerable to decline in the physical, psych-social, and economical functions in a different experience which may interfere negatively with their quality of life satisfaction by different levels. Besides, with increase in older adults' age, the elderly become more susceptible to chronic illnesses which have a direct effect on the functional ability to perform the activities of daily living and the instrumental activities of daily living.

According to the gender and quality of life, the result of the current study revealed that there is a significant correlation between gender and QOL. Furthermore, the males had the highest percent of QOL than females. This result was in agreement with the other studies like Eucharia \& Sam, 2015; Unsar, Erol \& Sut, 2016; Rashid $\&$ Tahir, 2014) who displayed that the women had poor quality of life compared to the men because the percentage of the chronic diseases were detected among elderly women more than the men. Conversely, some other studies (Pradeep, Sariyamon \& Jiraporn, 2017; Laleh, Hamideh \& Arash, 2017; Yodmai, Somrongthong \& Kumar, 2018) reported that who showed that gender had no impact on the quality of life among the elderly population. This difference may be related to the increasing number of life expectancy among women than men that leads to women having more experience in physiological, social, economic and psychological changes which increases susceptibility to chronic illnesses and decrease their functional capacity to perform ADL and IADL.

The present study illustrated that the marital status, patterns of living arrangement and types of care providers' factors have a positive significant association with quality of life satisfaction. In addition, there is a high percentage of the older adults' participants who are 
married and have a good quality of life satisfaction compared to those who are single, divorced, and widowed. Also as shown in the results, the older participants who are living with family had a good level of QOL satisfaction compared to the older participants who are living with their significant relative or living with home-made. Furthermore, the older adults' participants who received care from their children and spouse had the highest percent of QOL satisfaction compared to the participants who received care from nurse. This result is supported by (Pradeep, Sariyamon \& Jiraporn, 2017; Sereyraksmey \& Supaporn, 2017; Laleh, Hamideh \& Arash, 2017; Rashid \& Tahir, 2014; Yodmai, Somrongthong \& Kumar, 2015) who confirmed that married older people had a higher QOL compared to other groups who are single, divorced, widowed. On the other hand, the elderly people who are living with their family members, particularly spouses and children, had a better quality of life compared to those who are living alone or with the other significant relative as well as who are received care from house-made or nurses.

The results of the current study showed that there are positive correlations between QOL and levels of education and also family income. Literate older adults' participants with sufficient family income had better QOL compared to those who are illiterate and have insufficient family income. These results come in agreement line with Yodmai, Somrongthong \& Kumar, 2015; Sereyraksmey \& Supaporn, 2017; Michelle et al., 2016; Eucharia \& Sam, 2015; Harkirat, Kaur \& Venkateashan., 2015; Rashid \& Tahir, 2014, who reported that there is a direct relationship between level of education and QOL where the quality of life was higher among the older participants who have master or $\mathrm{Ph} . \mathrm{D}$. degree than the other who have diploma and bachelor degree. Besides, the older participants who have low education are less familiar with problemsolving methods and positive coping strategies. Also, the older people who have a poor socio-economic condition experience stress and as a result low QOL. The current study comes in contrast with Laleh, Hamideh \& Arash, 2017; Knodel \& Chayovan, 2008; Ahmadi, Salar \& Faghihzadeh, 2004; Avis et al., 2004 who illustrated that there was no association between QOL and level of education. In other studies, it was reported that there no significant difference between sex, education level, average income, current working status, and sufficient life expenses and QOL. Moreover, this study found that financial support from family which was not associated with QOL because aging people were financially supported by the government welfare and also the greater source of income among aging individuals was subsided from children and the second source was their work.

The result of the current study reflected that there is a significant positive correlation between the quality of life satisfaction and self-rated health. These results were congruent with Eucharia \& Sam, 2015; Wu et al., 2013; Cramm Van Dijk \& Nieboer, 2012; Amao, 2012 who stated that the prevalence of poor self-rated health among elderly tends to reflect poor ratings of quality of life especially health facilities and public utilities.

The result of the current study reflected that there is a significant positive correlation between the quality of life satisfaction and overall social support. Likewise, this result was in agreement with Pradeep, Sariyamon \& Jiraporn, 2017; Emmanuelle et al., 2016; Unsar, Dindar \& Kurt, 2015; Das et al., 2014) who mentioned that social support was significantly associated with increased quality of life, and also those older adult participants with high social support from spouse, partner, children, and friends were associated with good health and increased levels of well -being by the way of providing effective support, increasing self-esteem and enhancing mutual support.

The result of the current study reflected that there was a significant positive correlation between the quality of life satisfaction and all social support dimensions. This result is in the same line with Kumar et al., 2012; Bøen 2012; Hung, Kempen \& Vries, 2010 who specified that social support is a significant factor for emotional, spiritual, physical and psychological well- being of the older people. Moreover, older people with high levels of social support in maintaining good health. This will improve well-being of the older population and maximize their health and functional capacity as well as improve quality of life. Conversely, lack of social support can lead to a decline in self-esteem, increase psychological stress with a feeling of insecurity and uncertainty.

\section{REFERENCES}

Ahmadi F., Salar A. \& Faghihzadeh, S. (2004). Quality of life in Zahedan elderly population. Journal of Hayat, 10(3), pp 61-67. 
Amao, F.L. (2012). Urbanization, housing quality and environmental degeneration in Nigeria. Journal of Geography and Regional Planning, 5(16), pp 422-429.

Avis, N.E., Assmann, S.F., Kravitz H.M., Ganz, P.A. \& Ory, M. (2004). Quality of life in diverse groups of midlife women: assessing the influence of menopause, health status and psychosocial and demographic factors. Quality of Life Research, 13(5), pp 933-946.

Bélanger, E., Ahmed, T., Vafaei, A., Curcio, C.L., Phillips, S.P. \& Zunzunegui, M.V. (2016). Sources of social support associated with health and quality of life: a cross-sectional study among Canadian and Latin American older adults. BMJOpen, 6(6), e011503.

Bjorner, J.B., Søndergaard Kristensen, T., Orth-Gomér, K., Tibblin, G., Sullivan, M. \& Westerholm, P. (1996). SelfRated Health: A Useful Concept in Research, Prevention and Clinical Medicine. Stockholm: The Swedish Council for Planning and Coordination of Research, Report No.: 96:9.

Bøen, H. (2012). Characteristics of senior center users - and the impact of a group program on social support and latelife depression. Norsk Epidemiologi, 22(2), 261-269.

Bryła, M., Burzyńska, M. \& Maniecka-Bryła, I. (2013). Self-rated quality of life of city-dwelling elderly people benefitting from social help: results of a cross-sectional study. Health and Quality of Life Outcomes, 11: 181.

Cramm, J.M., Van Dijk, H.M. \& Nieboer A.P. (2012). The importance of neighborhood social cohesion and social capital for the well-being of older adults in the community. The Gerontologist, 53(1), pp 142-52.

Dangi, A. (2016). Factors Associated with Self-Rated Health Among Elderly People Living in Old Age Homes of Kathmandu Valley, Nepal. Oslo and Akershus University College of Applied Sciences, Oslo and Akershus University College of Applied Sciences, Faculty of Social Sciences, pp 8-30.

Das, J., Farzana, F.D., Ferdous, F., Ahmed, S., Tegenfeldt, S., Paul, R.C. \& Das, S.K. (2014). Factors associated with elderly depression among rural Bangladeshi individuals. American Journal of Psychiatry and Neuroscience, 2(1), 1-7.

Eucharia, O.E. \& Sam, O. (2015). The relationship between urban-dwelling older adults' satisfaction with the environmental quality of life and self-rated health in a Nigerian setting. International Journal of Development and Sustainability, 4(8), pp 872-885.

Faul, F., Erdfelder, E., Lang, A.G. \& Buchner, A. (2009). G*Power 3: A flexible statistical power analysis program for the social, behavioral, and biomedical sciences. Behavior Research Methods, 39(2), pp 175-191.

Harkirat, K., Kaur, H. \& Venkateashan, M. (2015). Factors determining family support and quality of life of the elderly population. International Journal of Medical Science and Public Health, 4(8), pp 1049-53.

Hung, L-W., Kempen, G. \& Vries, N.K.D. (2010). Cross-cultural comparison between academic and lay views of healthy aging: a literature review. Aging and Society, 30(8), pp 1373-91.

Kaplan, G.A. \& Camacho, T. (1983). Perceived health and mortality: a nine-year follow-up of the human population laboratory cohort. American Journal of Epidemiology, 117(3), pp 292-304.

Karlin, N., Weil, J. \& Felmban, W. (2016). Aging in Saudi Arabia. Gerontology \& Geriatric Medicine, 3, pp 1-9.

Katz, S., Down, T.D., Cash, H.R. \& Grotz, R.C. (1970). Progress in the development of the index of ADL. The Gerontologist,10(1), pp 20-30.

Knodel, J. \& Chayovan, N. (2008). Older Persons in Thailand: A demographic, social and economic profile. Ageing International,33(1), pp 3-14.

Kobayashi, T., Kawachi, I., Iwase, T., Suzuki, E. \& Takao, S. (2013). Individual-level social capital and self-rated health in Japan: an application of the resource generator. Social Science \& Medicine, 85, pp 32-7. 
Kumar, S., Calvo, R., Avendano, M., Sivaramakrishnan, K. \& Berkman, L.F. (2012). Social support, volunteering, and health around the world: cross-national evidence from 139 countries. Social Science \& Medicine, 74(5), pp 696-706.

Laleh G.E., Hamideh, A.R. \& Arash, T. (2017). Factors Affecting Quality of Life among Elderly Population in Iran. Humanities and Social Sciences, 5(1), pp 26-30.

Lawton, M.P. \& Brody, E.M. (1969). Assessment of older people: Self-maintaining and instrumental activities of daily living. The Gerontologist, 9(3), pp 179-186.

Mária, S.S. (2016). Determinants of quality of life in the elderly. Central European Journal of Nursing and Midwifery, 7(3), pp 484-493.

Martinez-Martin, P., Prieto-Flores, M.E., Forjaz, M., Fernandez- Mayoralas, G., Rojo-Perez, F. \& Rojo, J.M. (2012). Components and determinants of quality of life in community-dwelling older adults. European Journal of Ageing, 9(3), pp 255-263.

Michelle, H.P.P., Maycon, S.P., Janaína, S.N. \& Álvaro, S.S. (2016). Factors associated with quality of life among the elderly in the community of the southern triangle macro-region, Minas Gerais, Brazil. Ciência \& Saúde Coletiva, 21(11), pp 3347-3356.

Mohammad, A. U., Pratum, S., Duangruedee, L., Phanida, J. (2017). Factors related to the quality of life among older adults in Bangladesh: A cross-sectional survey. Nursing \& Health Sciences, 19(4), pp 518-524.

Porta, M. (2008). A Dictionary of Epidemiology. USA: Oxford University Press.

Pradeep, G.C., Sariyamon, T. \& Jiraporn, C. (2017). Factors associated with quality of life among the elderly in Baglung District, Nepal. Journal of Public Health and Development, 15(3), pp 51-64.

Raggi, A., Corso, B., Minicuci, N., Quintas, R., Sattin, D., De Torres, L., Chatterji, S., Frisoni, G.B., Haro, J.M., Koskinen, S., Martinuzzi, A., Miret, M., Tobiasz-Adamczyk, B. \& Leonardi, M. (2016). Determinants of the quality of life in aging populations: results from a cross-sectional study in Finland, Poland, and Spain. PLoS ONE, 11(7), e0159293.

Rashid, A.K. \& Tahir, I. (2014). Influence of Social Factors to the Quality of Life of the Elderly in Malaysia. Open Medicine Journal, 1, 29-35.

Saudi Arabia-World Bank Data (2019). World Bank Group. Retrieved from: https://data.worldbank.org/country/saudiarabia

Saxena, P.C. (2008). Ageing and age-structural transition in the Arab countries: regional variations, socioeconomic consequences and social security. Università degli Studi di Roma "La Sapienza”. Genus, 64(1/2), pp 37-74.

Sereyraksmey, L. \& Supaporn, S. (2017). Quality of life among elderly people in Kampong Cham Province, Cambodia. Southeast Asian Journal of Tropical Medicine and Public Health, 48(4), pp 884-891.

Sherbourne, S.D. \& Stewart, A.L. (1991). The MOS social support survey. Social Science \& Medicine, 32(6), pp 705-14.

Skevington, S.M., Lofty, M. \& O'Connell, K.A. (2004). The World Health Organization's WHOQOL-BREF quality of life assessment: psychometric properties and results of the international field trial. A report from the WHOQOL group. Quality of Life Research, 13(2), pp 299-310.

Tavares, D.M.S., Santos, L.L., Dias, F.A., Ferreira, P.C.S. \& Oliveira, E.A. (2015). Quality of life of rural elderly and associated factors. Journal of Nursing, 9(11), pp 9679-9687.

The World Population Prospects (2019). World Population Prospects. United Nation: Desa/ Population Division. Retrieved from: http://esa.un.org/unpd/wpp/.

United Nations, Department of Economic and Social Affairs, Population Division (2015). Population 2030: 
Demographic challenges and opportunities for sustainable development planning (ST/ESA/SER.A/389). United Nations, New York.

Unsar S., Erol, O. \& Sut, N. (2016). Support and Quality of Life among Older Adults. International Journal of Caring Sciences, 9(1), pp 249-257.

Unsar, S., Dindar, I. \& Kurt, S. (2015). Activities of daily living, quality of life, social support and depression levels of elderly individuals in Turkish society. Journal of Pakistan Medical Association, 65(6), pp 642-646.

White, A.M., Philogene, G.S., Fine, L. \& Sinha, S. (2009). Social Support and Self-Reported Health Status of Older Adults in the United States. American Journal of Public Health, 99(10), pp 1872-1878.

WHOQOL User Manual. Geneva, Switzerland (1997). Quality of life, a short questionnaire, Arabic version, May, Program of public health, Unicef.

World Health Organization (2015). World Report on Ageing and Health. Geneva: WHO. Available at: https://www.who.int/ageing/events/world-report-2015-launch/en/

Wu, S., Wang, R., Zhao, Y., Ma, X., Wu, M., Yan, X. \& He, J. (2013). The relationship between self-rated health and objective health status: a population-based study. BMC public health, 13:320.

Yodmai, K., Somrongthong, R. \& Kumar, R. (2018). Determinants of Quality of Life among Rural Elderly Population in Khonkean Province of Thailand. Journal of Liaquat University of Medical \& Health Sciences, 17(03), 180-184. 